\title{
Penerapan Model Teaching Games For Understandimg dalam Permainan Sepakbola di Sekolah Dasar
}

\author{
Belly Siska Jaya ${ }^{1}$, Andi Suntoda ${ }^{2}$, Didin Budiman ${ }^{2}$ \\ ${ }^{1}$ Sekolah Dasar Negeri 03 Sijuk, Indonesia \\ ${ }^{2}$ Universitas Pendidikan Indonesia, Indonesia
}

Info Artikel
SejarahArtikel:
Diterima Agustus 2019
Disetujui September2019
Dipublikasikan Oktober 2019
Keywo............................................................
Teaching Games For Understanding,
Sepakbola

\section{Abstrak}

Studi ini bertujuan untuk meningkatkan keterampilan bermain sepakbola dan meningkatkan kerjasama siswa kelas V SDN Sijuk melalui penerapan Teaching Games For Understanding (TGFU). Metode yang digunakan dalam penelitian ini adalah Penelitian Tindakan Kelas, dengan 4 kali tindakan dan 2 siklus. Untuk mengukur keterampilan bermain sepakbola penelitian menggunakan Games Performance Assessment Instrument dan untuk mengukur nilai kerjasama siswa diukur menggunakan angket. Partisipan sebanyak 22 siswa kelas 5 SDN 03 Sijuk Kab Belitung. Hasil penelitian menunjukan bahwa terdapat peningkatan keterampilan bermain sepakbola. Hasil penelitian ini, juga menunjukan terdapat peningkatan nilai kerjasama siswa. Hasil penelitian diharapkan dapat memberikan informasi kepada guru maupun praktisi pembinaan olahraga anak usia dini, untuk meningkatkan keterampilan bermain dan kerjasama siswa melalui penerapan TGFU.

\begin{abstract}
This study aims to improve football playing skills and improve the cooperation of fifth grade students at SDN Sijuk through the application of Teaching Games For Understanding (TGFU). The method used in this research is Classroom Action Research, with 4 actions and 2 cycles. To measure research football playing skills using the Games Performance Assessment Instrument and to measure the value of student cooperation is measured using a questionnaire. Participants were 22 grade 5 students of SDN 03 Sijuk, Belitung Regency. The results showed that there was an increase in football playing skills. The results of this study also showed an increase in the value of student collaboration. The results of the study are expected to provide information to teachers and practitioners of early childhood sports development, to improve students' play skills and collaboration through the application of TGFU.
\end{abstract}




\section{PENDAHULUAN}

Pendidikan jasmani adalah proses pendidikan melalui aktivitas jasmani, permainan dan olahraga yang terpilih untuk mencapai tujuan pendidikan (Mahendra, 2015). Dalam proses pelaksanaan pembelajaran pendidikan jasmani memiliki tujuan. Tujuan dari pendidikan jasmani diklasifikasikan kedalam empat kategori yang terdiri; (1) perkembangan fisik, (2) perkembangan gerak, (3) perkembangan mental, (4) perkembangan sosial (Bucher, 2016). Dalam kaitan ini diartikan bahwa pendidikan jasmani memiliki peran penting dalam dunia pendidikan. Pendidikan jasmani membentuk fisik, mental, serta emosional anak menjadi berkembang.

Pada upaya mencapai tujuan pembelajaran penjas, guru penjas dituntut untuk memiliki pengetahuan serta pemahaman yang baik mengenai model-model pembelajaran dalam pendidikan jasmani. Model pembelajaran merupakan langkah yang digunakan dalam kegiatan pembelajaran, juga sebagai acuan guru agar tercapai tujuan yang ingin dicapai. Model pembelajaran adalah suatu penyajian fisik atau konseptual dari sistem pembelajaran, serta berupaya menjelaskan keterkaitan berbagai komponen sistem pembelajaran ke dalam suatu pola atau kerangka pemikiran yang disajikan secara utuh (Juliantine, dkk, 2015). Dari pengertian ini dapat disimpulkan bahwa model pembelajaran adalah penyajian baik berupa bentuk ataupun konseptual yang didalamnya mengandung kerangka pemikiran pembelajaran yang akan disampaikan oleh guru. Terdapat beberapa model pembelajaran dalam pendidikan jasmani salah satunya adalah model Teaching Games for Understanding (TGFU), model ini menerapkan pembelajaran permainan untuk meningkat- kan pemahaman bermain. Model Teaching Games for Understanding (TGFU) merupakan suatu model pembelajaran pendidikan jasmani untuk memperkenalkan bagaimana anak mengerti olahraga melalui bentuk konsep dasar bermain (Pujianto, 2014). Dalam kaitan ini model pembelajaran Teaching Games for Understanding (TGFU) menuntut siswa mengerti akan konsep bermain dalam pembelajaran pendidikan jasmani.

Bermain pada intinya adalah aktivitas yang digunakan sebagai hiburan. Dari kata bermain lalu lahir kata permainan, yang diartikan sebagai aktifitas fisik yang didalamnya sudah mengandung unsur-unsur yang menyenangkan. Dalam pendidikan jasmani, ketika tujuan dari permainan dikaitkan dengan tujuan pembelajaran penjas, permainan yang dimaksud tentu harus yang bercirikan aktivitas jasmani, yaitu gerak yang selalu melibatkan penggunaan otot besar dan memerlukan energi yang sangat besar dalam melakukan pergerakannya. Banyak sekali bentuk permainan dalam pembelajaran penjas, salah satunya adalah permainan sepokbola. Sepakbola merupakan permainan yang dilakukan oleh 11 pemain diantaranya terdapat satu penjaga gawang. Dalam upaya mencapai tujuan pembelajaran pendidikan jasmani penerapan model pembelajaran sangatlah berpengaruh dalam mencapai tujuan pembelajaran. Sekarang ini banyak penelitian yang meneliti tentang model pembelajaran dalam pembelajaran penjas, salah satunya Penelitian Tindakan Kelas (PTK) yang telah dilakukan oleh Chan dan Indrayeni (2018) menunjukkan bahwa Pendekatan pendekatan Teaching Games for Understanding (TGFU) dapat meningkatkan kemampuan passing bawah dalam permainan bola 
voli pada siswi kelas VIII di SMP Negeri 11 Muaro Jambi.

\section{METODE}

Metode yang digunakan dalam penelitian ini yaitu metode Penelitian Tindakan Kelas (PTK). Penelitian ini dilakukan dengan 2 siklus, setiap siklus terdiri dari 2 tindakan, setiap tindakan dilakukan sebanyak satu pertemuan. Sampel penelitian adalah siswa kelas V SDN 03 Sijuk, Kabupaten Belitung, Kepulauan Bangka Belitung yang berjumlah 22 siswa , 13 siswa laki-laki dan 9 siswa perempuan. Instrumen yang digunakan untuk mengukur keterampilan bermain siswa dalam permainan sepakbola menggunakan alat ukur GPAI (Games Performance Assesment Instrument) dalam sepakbola (Griffin, dkk, 1997)

\section{HASIL DAN PEMBAHASAN}

Keterampilan bermain melalui penerapan model pembelajaran Teaching Games for Understanding (TGFU) dalam permainan sepakbola di sekolah dasar ditunjukkan pada Gambar 1

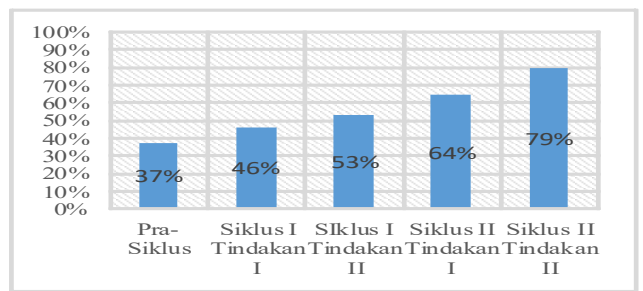

Gambar 1.

Presentase Hasil Keterampilan Bermain

Berdasarkan diagram diatas hasil keseluruhan penelitian dari mulai prasiklus (observasi awal) sampai dengan siklus II tindakan II diketahui bahwa penerapan model Teaching Games for Understanding (TGFU) dalam permainan sepakbola di sekolah berhasil meningkatkan keterampilan bermain sepakbola, terlihat dari setiap tindakan dari siklus I sampai siklus II yang dilakukan mengalami kenaikan yaitu dari $37 \%, 46 \%, 53 \%, 79 \%$.

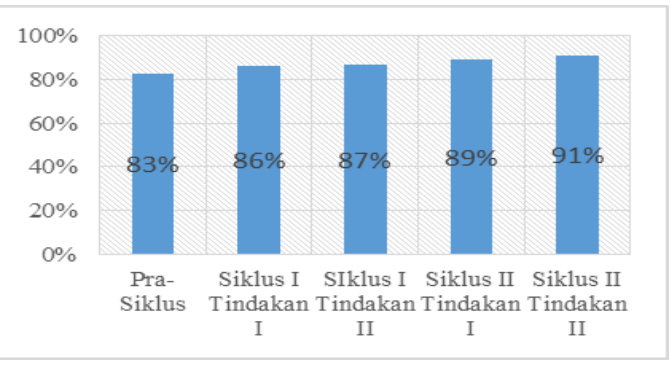

Gambar 2

Presentase Aspek Kerjasama Siswa

Dilihat dari Gambar 2 bahwa penerapan model Teaching Games for Understanding (TGFU) dalam permainan sepakbola di sekolah dasar berhasil meningkatkan nilai kerjasama siswa, terlihat dari setiap tindakan dari siklus I sampai siklus II yang dilakukan mengalami kenaikan yaitu dari $86 \%, 87 \%$, $89 \%, 91 \%$.

Hasil penelitian yang digambarkan pada grafik 1 dan 2 menunjukkan peningkatan keterampilan bermain dan kerjasama pada siswa. Hal ini selaras dengan penelitian sebelumnya yang menunjukkan keterkaitan model pembelajaran taktis dengan peningkatan motivasi dan intensitas gerak (Stephani, dkk, 2019).TGFU menjadi salah satu dasar pengembangan model pembelajaran taktis, sehingga keterkaitan TGFU pada penelitian ini berkaitan erat dengan peningatan keterampilan bermain dan kerjasama yang sama-sama didasari oleh aspek motivasi.

\section{KESIMPULAN}

Penerapan Teaching Games for Understanding (TGFU) dapat meningkatkan keterampilan bermain sepak bola dan kerjasama siswa kelas 5 SDN 03 Sijuk, Kab Belitung. 


\section{DAFTAR PUSTAKA}

Chan, F dan Indrayeni, Y. (2018). Meningkatkan Kemampuan Passing Bawah dalam Permainan Bola Voli Melalui Pendekatan TGFU pada Siswa Kelas VIII SMP NEGERI 11 MUARO JAMBI 2. Dalam Jurnal Physical Education, Health and Recreation; Vol. 2 No. 2. [online]. Tersedia di https:// jurnal.unimed.ac.id.

Griffin,S. A. Michell, dan J.L Oslin, 1997, Teaching sport Concepts and Skills: A Taching Games. USA: Human Knicetics

Haft. Jan (2003). Training and Testing Physical Capacities for Elite Soccer Player. Journal of Sport Science,23(6) : 573-582.

Juliantine, dkk. (2015). Model-Model Pembelajaran dalam Pendidikan Jasmani. Bandung: CV. Bintang Warliartika.

Mahendra, A. (2015). Filsafat Pendidikan Jasmani Dasar-Dasar Pembelajaran Penjas di Sekolah Dasar. Bandung: CV. Bintang Warliartika

Stephani, M. R., Nur, L., Hambali, B., Suherman, A., \& Subarjah, H. Comparative Analysis of Student Learning Motivation and Motion Intensity in Tactical and Technical Learning Models in Invation Games. JURNAL PENDIDIKAN JASMANI DAN OLAHRAGA, 4(2), 225230. 